\title{
The effect-site concentration of propofol producing respiratory depression during spinal anesthesia
}

\author{
Mi Hyeon Lee, Ki-Hwan Yang, Choon Soo Lee, Hong Sik Lee, Sin Yeong Moon, Sung-Il Hwang, \\ and Jang-Ho Song
}

Department of Anesthesiology and Pain Medicine, College of Medicine, Inha University, Incheon, Korea

Background: Propofol is used worldwide for its sedative effective; nonetheless, has the serious side effect of respiratory depression. An increased blood concentration of propofol is well known to be associated with increased respiratory depression. However, there are no studies of the effect site concentration inducing respiratory depression. The purpose of this study was to determine the effect site concentration inducing respiratory depression of propofol when sedating a patient after spinal anesthesia.

Methods: This study included thirty seven males who received operations with spinal anesthesia, which was performed on L3-4 and L4-5. All patients were monitored with the bispectral index and were continuously infused with propofol using target controlled infusion. Respiratory depression was diagnosed when one of the following was evident without upper respiratory obstructive signs: a greater than $20 \%$ increase of end tidal carbon dioxide from baseline pressure or pulse oximetry oxygen saturation lower than $95 \%$. We obtained the $\mathrm{EC}_{5}, \mathrm{EC}_{10}$, and $\mathrm{EC}_{50}$ of the effect site propofol for respiratory depression.

Results: The $\mathrm{EC}_{5}$ of propofol for respiratory depression was $3.09 \mathrm{mcg} / \mathrm{ml}(95 \% \mathrm{CI}, 2.60-3.58)$. The $\mathrm{EC}_{10}$ of propofol for respiratory depression was $3.18 \mathrm{mcg} / \mathrm{ml}(95 \% \mathrm{CI}, 2.57-3.80)$. The $\mathrm{EC}_{50}$ of propofol for respiratory depression was 3.99 $\mathrm{mcg} / \mathrm{ml}$ (95\% CI, 2.36-5.61).

Conclusions: The $\mathrm{EC}_{5}, \mathrm{EC}_{10}$, and $\mathrm{EC}_{50}$ of effect site propofol for respiratory depression during spinal anesthesia were $3.09 \mathrm{mcg} / \mathrm{ml}, 3.18 \mathrm{mcg} / \mathrm{ml}$, and $3.99 \mathrm{mcg} / \mathrm{ml}$, respectively. (Korean J Anesthesiol 2011; 61: 122-126)

Key Words: Propofol, Respiratory insufficiency, Spinal anesthesia.

\footnotetext{
Received: September 6, 2010. Revised: 1st, November 8, 2010; 2nd, December 31, 2010; 3rd, January 23, 2011; 4th, January 30, 2011; 5th, February 4, 2011. Accepted: February 5, 2011.

Corresponding author: Jang-Ho Song, M.D., Department of Anesthesiology and Pain Medicine, College of Medicine, Inha University, 7-206, Sinheung-dong 3-ga, Jung-gu, Incheon 400-711, Korea. Tel: 82-32-890-3968, Fax: 82-32-881-2477, E-mail: snoguy@naver.com

(ㄷ) This is an open-access article distributed under the terms of the Creative Commons Attribution Non-Commercial License (http:// creativecommons.org/licenses/by-nc/3.0/), which permits unrestricted non-commercial use, distribution, and reproduction in any medium, provided the original work is properly cited.
} 


\section{Introduction}

Propofol is widely used for anesthesia and sedation purposes because of its amnesic effect, fast recovery, and low incidence of nausea and vomiting [1]. Propofol, however, has the shortcoming of severe respiratory depression, including a decrease in ventilatory response to hypoxia and in tidal and minute volumes [2]. Blouin et al. [3] reported that propofol increased the blood carbon dioxide tension, decreased the hydrogen ion concentration index, and decreased the ventilatory response to hypoxia.

In a study using target-controlled infusion (TCI), Kim et al. [4] reported that both the frequency of airway obstruction and the carbon dioxide concentration in the arterial blood increased as the target effect site concentration increased. In the study conducted by Kim et al., it was estimated that the effect site concentrations that caused airway obstruction in $50 \%$ of the patients $\left(\mathrm{EC}_{50}\right)$ consisting of non-smokers and smokers were $2.6(1.5-9.4)$ and $0.9(-9.3) \mu \mathrm{g} / \mathrm{ml}$, respectively. The results of the study conducted by Kim et al., however, include airway obstruction as well as respiratory depression, such as apnea.

It has been observed that in the case of the infusion of propofol for sedation after regional anesthesia in the actual operating room, if the sensitivity to propofol is weak, or if the excessive movement of the patient even after anesthesia interferes with the surgical operation, the dose of propofol is sometimes increased while airway obstruction is rectified via triple airway maneuver. As such, this study was conducted to determine the effect site concentration of propofol at which respiratory depression would occur regardless of airway obstruction in the case of the continuous infusion of propofol using TCI, by assuming that the airway-obstructing propofol dose and the respiratory-depressing propofol dose are different when propofol is used for a patient who breathes spontaneously.

\section{Meterials and Methods}

The study included 37 patients aged 20 to 65 years old, who were classified as status 1 or 2 according to the Physical-Status Classification of the American Society of Anesthesiologists, and who were to receive surgery under spinal anesthesia (Table 1).

Approval was obtained from the Ethics Committee for Clinical

Table 1. Patients' Demographic Data

\begin{tabular}{lc}
\hline Age (year) & $37.18 \pm 13.42$ \\
\hline Height $(\mathrm{cm})$ & $171.81 \pm 6.94$ \\
Weight $(\mathrm{kg})$ & $70.32 \pm 13.54$ \\
Body mass index & $24.14 \pm 2.76$ \\
\hline
\end{tabular}

Trials, and informed consent was obtained from each of the patients. Excluded from the study were patients who were obese, who had a body mass index (BMI) of 30 or above, who were Mallampatti class III or above, or who showed hearing loss, a history of sedative use, or a history of sleep apnea, respiratory disease, or upper-respiratory infection within the past three weeks. No drug was administered before anesthesia.

Upon each patient's arrival at the operating room, spinal anesthesia was performed on L3-4 and L4-5 in the lateral recumbent position while the electrocardiogram, blood pressure (BP), and peripheral arterial oxygen saturation were being monitored. The patients whose sensory-extinction levels were T6 or above when tested with an alcohol swab were excluded from the study. Oxygen ( $5 \mathrm{~L} / \mathrm{min}$ ) was supplied through the nasal cavity, and the end-expiratory carbon dioxide tension was monitored through one of the nostrils.

After ensuring that an adequate level of anesthesia was obtained, intravenous infusion of $2 \%$ lidocaine ( $40 \mathrm{mg}$ ) was given, and propofol was continuously intravenously infused using a target-controlled infusion system (Base Prima Orchestra, Fresenius Vial, France). The target effect site concentration was determined for each patient, using the Schnidr model.

The target effect site concentration was determined using the up-and-down method. For the first patient in the study, the initial target effect site concentration was $2 \mathrm{mcg} / \mathrm{ml}$. When respiratory depression occurred, the target effect site concentration was reduced by $0.2 \mathrm{mcg} / \mathrm{ml}$ for the next patient. In contrast, when no respiratory depression occurred, the target effect site concentration of the previous patient was increased by $0.2 \mathrm{mcg} / \mathrm{ml}$ for the next patient.

Ten minutes after the propofol concentration reached the target effect site concentration, the bispectral index (BIS), oxygen saturation, and end-expiratory carbon dioxide tension were recorded with 30 -second intervals, and the pulse rate, respiratory rate, and $\mathrm{BP}$ were measured.

When airway obstruction occurred before or after the propofol concentration reached the target effect site concentration, the aforementioned variables were measured after waiting for at least 3 minutes and after checking that no airway obstruction occurred after repositioning the patient or inserting an oral airway. Here, airway obstruction was defined as a case in which end-expiratory carbon dioxide tension was not detected for 10 seconds or more based on the accompanying snoring or spurasternal notch, air flow was not detected, and the airway could be maintained via a three-way airway maneuver.

When the average arterial BP was $60 \mathrm{mmHg}$ or less or decreased by $30 \%$ or more from the baseline BP, 4 mg ephedrine was intravenously injected. When the heart rate was 45 beats or less per minute, $0.5 \mathrm{mg}$ atrophine sulfate was intravenously injected. 
Respiratory depression was defined as the case in which the end-expiratory carbon dioxide tension increased by $20 \%$ or more from the pre-sedation end-expiratory carbon dioxide tension without upper-airway obstruction symptoms, or in which the oxygen saturation decreased to below $95 \%$.

The patients' ages, heights, weights, and BMIs were expressed as mean $\pm \mathrm{SD}$, and the estimated effect site concentrations at which respiratory depression would occur in $5 \%\left(\mathrm{EC}_{5}\right), 10 \%$ $\left(\mathrm{EC}_{10}\right)$, and $50 \%\left(\mathrm{EC}_{50}\right)$ of the patients was determined by estimating the centered isotonic regression and PAVA using $\mathrm{R}$ : A Language and Environmental for Statistical Computing (ver. 2.11.1, R Foundation for Statistical Computing, Vienna, Austria). The BIS value by the target effect site concentration of propofol was tested using the Pearson correlation coefficient.

\section{Results}

In all the patients, the blocking level of the sensory nerve after spinal anesthesia was below T8. Respiratory depression did not occur at the propofol concentration of $3.6 \mathrm{mcg} / \mathrm{ml}$ but occurred in three of seven patients at $3.8 \mathrm{mcg} / \mathrm{ml}$, in four of seven patients at $4.0 \mathrm{mcg} / \mathrm{ml}$, in three of six patients at $4.2 \mathrm{mch} / \mathrm{ml}$, and in one patient at $4.6 \mathrm{mcg} / \mathrm{ml}$ (Fig. 1). Thus, the estimated effect site concentration of propofol that could cause respiratory depression in $5 \%\left(\mathrm{EC}_{5}\right)$ of the patients was $3.9 \mathrm{mcg} / \mathrm{ml}(95 \% \mathrm{CI}$, $2.60-3.58), 3.18 \mathrm{mcg} / \mathrm{ml}$ in $10 \%\left(\mathrm{EC}_{10}\right)$ of the patients $(95 \% \mathrm{CI}$, $2.57-3.80)$, and $3.99 \mathrm{mcg} / \mathrm{ml}$ in $50 \%\left(\mathrm{EC}_{50}\right)$ of the patients $(95 \%$ CI, 2.36-5.61) (Fig. 2).

Upper-airway obstruction occurred in 16 patients; among them, it occurred at the effect site concentration of $3.6 \mathrm{mcg} /$ $\mathrm{ml}$ or less in five patients, and the effect site concentrations at which upper-airway obstruction occurred ranged from $2.0 \mathrm{mcg} /$ $\mathrm{ml}$ to $4.4 \mathrm{mcg} / \mathrm{ml}$.

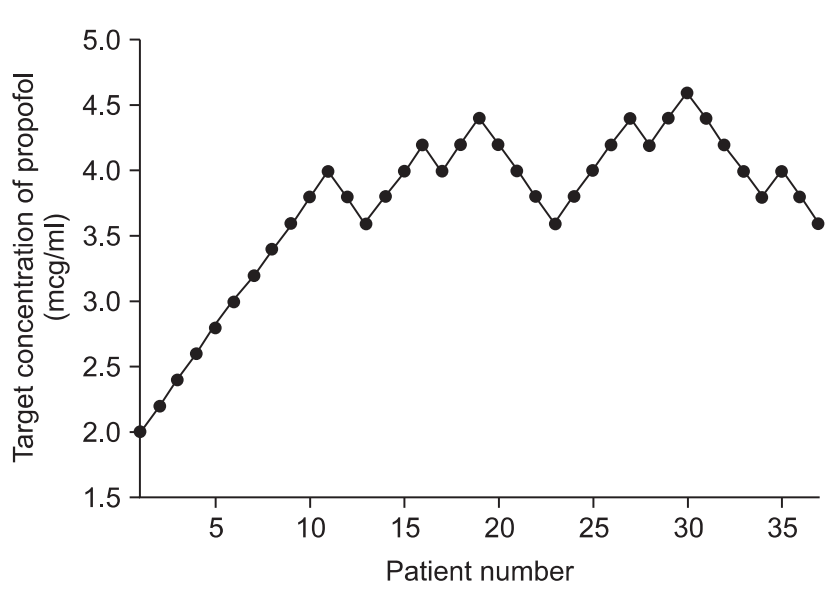

Fig. 1. Individual responses to the pre-determined effect site concentration of propofol.
In the patients in whom upper-airway obstruction occurred, respiration was maintained by performing a three-way airway maneuver or by using an airway maintenance device after repositioning the body.

In one patient who received $4.0 \mathrm{mcg} / \mathrm{ml}$ propofol, an adequate sedative effect was not achieved because the BIS was 90 or more. No correlation was found between the propofol concentration and BIS (Fig. 3). In none of the patients did the heart rate drop below $45 \mathrm{bpm}$ or less. At the effect site concentrations of $2.0 \mathrm{mcg} / \mathrm{ml}$ in one patient and $3.8 \mathrm{mcg} / \mathrm{ml}$ in one patient, ephedrine was intravenously infused as the BP dropped by $30 \%$ or more from the baseline.

\section{Discussion}

Propofol is widely used for anesthesia and sedation because

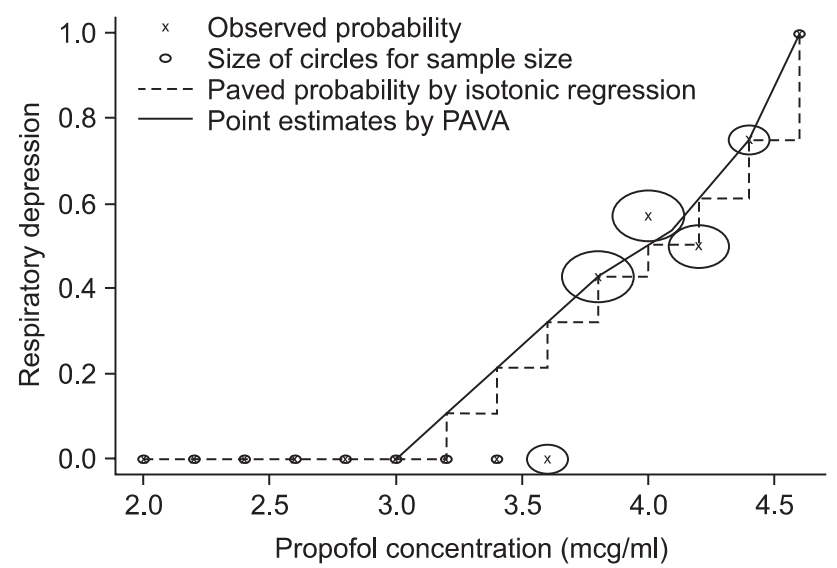

Fig. 2. Relationship between respiratory depression and the effect site concentration of propofol. $\mathrm{EC}_{5}$ value was $3.09 \mathrm{mcg} / \mathrm{ml}$ and $\mathrm{EC}_{50}$ value was $3.99 \mathrm{mcg} / \mathrm{ml}$.

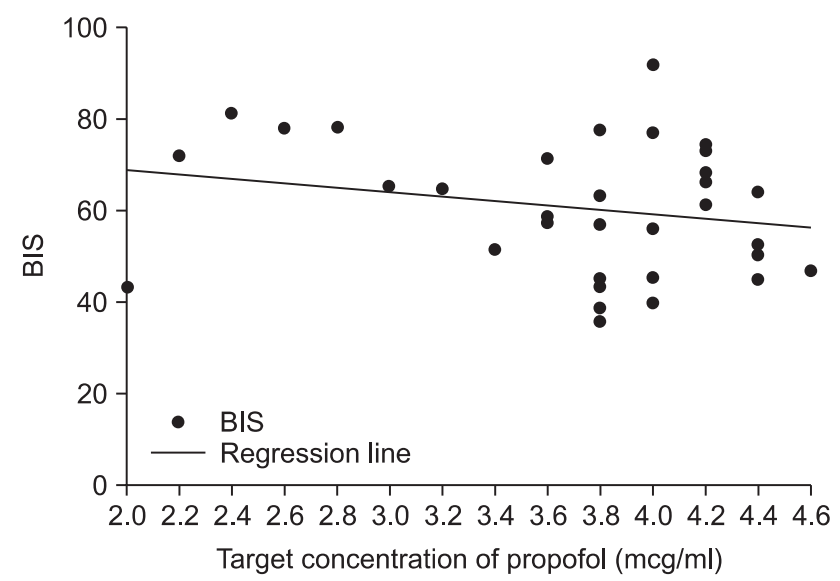

Fig. 3. The mean BIS value to the target concentration of propofol. The correlation between BIS and effect site concentration of propofol was not significant $(\mathrm{P}>0.05)$. 
of its advantages in allowing for fast recovery and a low occurrence rate of nausea and vomiting. An increase in the effect site concentration of propofol, however, can cause airway obstruction, respiratory depression, hypoxia, or an unstable hemodynamic response [5].

Propofol at a sedative dose can induce a decrease in the tidal volume, an increase in the respiratory rate, and a decrease in the inspiration cycle [2]. It is also known to cause ventilatory depression, such as a decreased ventilatory response or decreased heart beat response to hypoxia [6]. Yamakage et al. [7] reported that when sedation was performed with propofol, the tidal volume decreased by $60 \%$, and arterial-oxygen tension occurred due to paradoxical breathing caused by upper-airway obstruction.

Although the neurological mechanism by which propofol causes central-respiratory depression remains unclear, a study using a mouse reported that the GABA-receptor-mediated hyperpolarization of the pre-inspiratory neurons was involved in such a mechanism [8].

Vuyk et al. [9] reported that when propofol was solely used without premedication, the serum effect site concentration of porpofol required for inducing loss of consciousness in $50 \%$ and $60 \%$ of the patients were 3.4 and $4.3 \mathrm{mcg} / \mathrm{ml}$, respectively. Nishiyama [10] reported that the effect site concentration that induces loss of consciousness after spinal anesthetization is $1.9 \mathrm{mcg} / \mathrm{ml}$, and that the effect site concentration for proper sedation is $1.0-1.8 \mathrm{mcg} / \mathrm{ml}$.

In this study, the effect site concentration that induced respiratory depression was $3.8 \mathrm{mcg} / \mathrm{ml}$, and the $\mathrm{EC}_{5}, \mathrm{EC}_{10}$, and $\mathrm{EC}_{50}$ values that induced respiratory depression were 3.09, 3.18 , and $3.99 \mathrm{mcg} / \mathrm{ml}$, respectively. This shows that respiratory depression occurs at a certain concentration level of propofol, which is the same or higher than that required for spinal sedation [10].

This study also showed that respiratory depression that cannot be rectified via a three-way airway maneuver can occur at the effect site concentration of propofol that was identified by Kim et al. [4] to cause upper-airway obstruction. Pollock et al. [11] observed a decrease in the BIS value after spinal anesthetization, and reported that spinal anesthetization is related to the sedative effect of propofol. In addition, OzkanSeyhan et al. [12] reported that the dose of propofol required for inducing a loss of consciousness decreases as the anesthesia level increases in spinal anesthetization.

It is believed that spinal anesthesia can influence the effect site concentration as it plays a role in sedation. The limitation of this study is that the estimated effect site concentration that causes respiratory depression is restricted to patients who received spinal anesthesia, because all the study subjects received spinal anesthesia.
Kil et al. [13] reported that BIS was significantly related with respiratory depression according to the effect site concentration of propofol, and that the BIS value was $41.1 \pm$ 2.5 when the effect site concentration of propofol was $3.5 \mathrm{mcg} /$ $\mathrm{ml}$ in Koreans. In this study, the BIS value ranged from 80 to 40 at the propofol concentrations of $2.0-4.6 \mathrm{mcg} / \mathrm{ml}$, and no significant correlation was observed between BIS and propofol concentration. This is believed to be due to the small number of samples of the effect site concentration of propofol.

As this study was conducted to determine the effect site concentration of propofol that could induce respiratory depression using the up-and-down method, the effect site concentration that could cause sedation could not be determined. In addition, as the propofol concentration that is used only for sedation purposes but that could cause respiratory depression was not studied in patients who did not receive regional anesthesia, further studies are required for such.

In conclusion, the effect site concentrations of propofol that are used for sedation purposes via spinal anesthesization are 3.09, 3.18, and $3.99 \mathrm{mcg} / \mathrm{ml}_{\text {for }} \mathrm{EC}_{5}, \mathrm{EC}_{10}$, and $\mathrm{EC}_{50}$, respectively.

\section{Acknowledgements}

This work was supported by Inha University.

\section{References}

1. Veselis RA, Reinsel RA, Feshchenko VA, Wroński M. The comparative amnestic effects of midazolam, propofol, thiopental, and fentanyl at equisedative concentrations. Anesthesiology 1997; 87: 749-64.

2. Goodman NW, Carter JA, Black AM. Some ventilatory effects of propofol as a sole anaesthetic agent. Br J Anaesth 1987; 59: 1497503.

3. Blouin RT, Seifert HA, Babenco HD, Conard PF, Gross JB. Propofol depresses the hypoxic ventilatory response during conscious sedation and isohypercapnia. Anesthesiology 1993; 79: 1177-82.

4. Kim KS, Kim K, Lee SS, Yoo BH, Lee Y, Yon JH. The effect of cigarette smoking on propofol EC50 of airway obstruction during target controlled infusion of propofol. Korean J Anesthesiol 2005; 49: 25-9.

5. Lee YS. Effects of propofol target-controlled infusion on haemodynamic and respiratory changes with regard to safety. J Int Med Res 2004; 32: 19-24.

6. Nieuwenhuijs D, Sarton E, Teppema L, Dahan A. Propofol for monitored anesthesia care: implications on hypoxic control of cardiorespiratory responses. Anesthesiology 2000; 92: 46-54.

7. Yamakage M, Kamada Y, Toriyabe M, Honma Y, Namiki A. Changes in respiratory pattern and arterial blood gases during sedation with propofol or midazolam in spinal anesthesia. J Clin Anesth 1999; 11: 375-9.

8. Kashiwagi M, Okada Y, Kuwana S, Sakuraba S, Ochiai R, Takeda J. A neuronal mechanism of propofol-induced central respiratory depression in newborn rats. Anesth Analg 2004; 99: 49-55. 
9. Vuyk J, Engbers FH, Lemmens HJ, Burm AG, Vletter AA, Gladines MP, et al. Pharmacodynamics of propofol in female patients. Anesthesiology 1992; 77: 3-9.

10. Nishiyama T. Propofol infusion for sedation during spinal anesthesia. J Anesth 2007; 21: 265-9.

11. Pollock JE, Neal JM, Liu SS, Burkhead D, Polissar N. Sedation during spinal anesthesia. Anesthesiology 2000; 93: 728-34.

12. Ozkan-Seyhan T, Sungur MO, Senturk E, Karadeniz M, Basel
A, Senturk M, et al. BIS guided sedation with propofol during spinal anaesthesia: influence of anaesthetic level on sedation requirement. Br J Anaesth 2006; 96: 645-9.

13. Kil HY, Lee SI, Lee SJ, Lee SW, Lee DH. The bispectral index and modified observer's assessment of alertness/sedation scale comparable to effect site concentration of propofol in Koreans. Korean J Anesthesiol 2000; 38: 251-7. 